\title{
Steady State Torque Optimal Operating Point Control for Wound Rotor Synchronous Motors
}

\author{
David Uzel, Zdeněk Peroutka \\ The Regional Innovation Centre for Electrical Engineering (RICE) \\ University of West Bohemia \\ Pilsen, Czech Republic \\ duzel@rice.zcu.cz,pero@rice.zcu.cz
}

\begin{abstract}
This paper discusses steady state optimal control of the motor from the maximum torque point of view. The motor behavior is researched with a vector control supply in the full speed range. The optimal considerations are compared with a behavior of the classical control structures such as the unity power factor strategy.
\end{abstract}

Keywords-optimal operating point; wound rotor synchronous motor; maximum torque per ampere; maximum torque per flux; unity power factor

\section{INTRODUCTION}

The wound rotor synchronous machine (WRSM) became more frequentative during recent years due to the price increase of the permanent magnets, which are exclusively made by China. Another reason for the employment can be the pressure of the market system to innovate products with DC machine for regulated medium voltage drives. The drives operate with several megawatts of power so that the maximal effective using of energy is required. In order to achieve the optimality, the maximum torque operating point of the motor is sought and is set through the $\mathrm{d}$, qaxis stator currents and rotor field current as features [1]. Furthermore, the utilization of damper winding was considered and was avoided due to additional torque ripples and power losses.

In accordance with the torque equation (1), the reluctance torque cannot be utilized from the saturation reason [2]. The wound rotor has higher inductance in the d-axis then the q-axis $\mathrm{L}_{\mathrm{sd}}>\mathrm{L}_{\mathrm{sq}}$ (In the d-axis, the salient pole iron of the rotor has higher magnetic conductivity than the air gap in the q-axis), therefore the positive d-axis current has to be used for the reluctance utilization for the increasing of the total moment. As the surface permanent magnet synchronous motors (PMSMs) are controlled [3], [4], [5] the first idea how to optimally operate these wound motor is to keep the d-axis stator current to be zero up to the base speed, but it usually was not common even thirty years ago [6], [7], [8], [9]. The most utilized strategy is to orient the vector control on stator or magnetic flux linkage, where the field rotor current is higher than nominal and the d-axis stator current is negative. For right orientation, the mathematical motor model with parameters is used. The several known strategies use different approaches. The simplest methods operate with current flux model in $\mathrm{d}$, $\mathrm{q}$ rotor reference frame coordinates as [9]. The next utilizes the voltage motor model as the core of the phase lock loop estimator, see [10], where several adjustable filters are used for elimination of the DC drift at the back electromotive force. It solves the estimated flux fluctuation in the transition states. The paper [6] shows combined observer with the current and voltage mathematical models, where the current model corrects the input voltage of the voltage model. It solves the problem of the voltage model in the low speeds. Finally, the advanced solutions utilize a state observer as [7], which contains the voltage equations of the motor for determination of the stator flux linkage by the integration and the correction feedback uses the current model. This solution is presented as the stable observer for whole speed range of the rolling mill drive. Otherwise, the $\mathrm{d}$, q rotor reference frame can be used without any mathematical model or flux linkage estimator but the optimal operating points demonstrate nonzero $\mathrm{d}$-axis current (For the flux oriented control, the $\mathrm{d}_{\psi}$-axis current in the flux reference frame is kept zero up to the base speed) even up to the base speed. In the field weakening area, the rotor current decreasing to zero with the increase of the speed is considered. It is partially truth. The rotor current is slightly reduced, but not proportionally to the rotor speed. More dramatically, the d-axis stator current is lowered. Since the rotor reference frame is used (the frame angle is given from the position sensor), the challenge of the rightness flux linkage estimation is shifted to the generating of the rotor and stator current demands.

This contribution features the simulation study of the vector controlled motor with emphasis to the maximum torque. The results are compared with the classical approaches and discussed. Consequently, the simulations are verified on the developed laboratory prototype.

\section{THEORETICAL FOUNDATION}

\section{A. Mathematical analysis}

The fundamental considerations are made from the following torque equation:

$$
T=k_{p} p_{p}\left[\psi_{f} i_{s q}+\left(L_{s d}-L_{s q}\right) i_{s q} i_{s d}\right]
$$

$$
\begin{array}{ll}
\text {, where } & \\
T & \text { Electromagnetic torque, } \\
k_{p} & \text { Park's transformation constant, }
\end{array}
$$




$\begin{array}{ll}p_{p} & \text { Number of pole pairs, } \\ \psi_{f} & \text { Rotor field flux linkage, } \\ i_{f} & \begin{array}{l}\text { Rotor field excitation current } \\ \text { (recalculated on the stator side), }\end{array} \\ i_{s d}, i_{s q} & \begin{array}{l}\mathrm{d}, \mathrm{q}-\mathrm{axis} \text { components of stator } \\ \text { current vector, }\end{array} \\ L_{s d, L_{s q}} & \mathrm{~d}, \mathrm{q} \text {-axis stator inductances. }\end{array}$

The torque is dependent on all three currents $i_{\text {sd }}, i_{\text {sq }}, i_{f}$. The first part of the equation with the field flux linkage is called main torque part and the second part is known as the reluctance torque part. As the state of the art shows, the application of the positive $i_{\text {sd }}$ current is unusable due to saturation effect. The classical strategy is to overexcite the machine as is shown in the next Fig. 1.

The higher field flux linkage than nominal is applied through the rotor current. The nominal magnetic flux linkage in the air gap of the machine is ensured by the negative d-axis current. The only one assumption has to be assured, that the main torque increase is higher than the reluctance part decrease. Consequently, the optimal operating point is given by higher than nominal field current, negative d-axis current and adequate q-axis current. Up to the base speed, the usable area of the operating points is limited only by the maximum stator and rotor current. In the field weakening area, see Fig. 2, the ellipses of the minimal perforce field weak are the second limitation rule. In comparison with the PMSMs, this elliptic area is smaller with the speed increase as well, but shifted on the d-axis by the changing of the rotor current, because the $d$-axis center is given by:

$$
-\psi_{f} / L_{s d}=-L_{m d} i_{f} / L_{s d}
$$

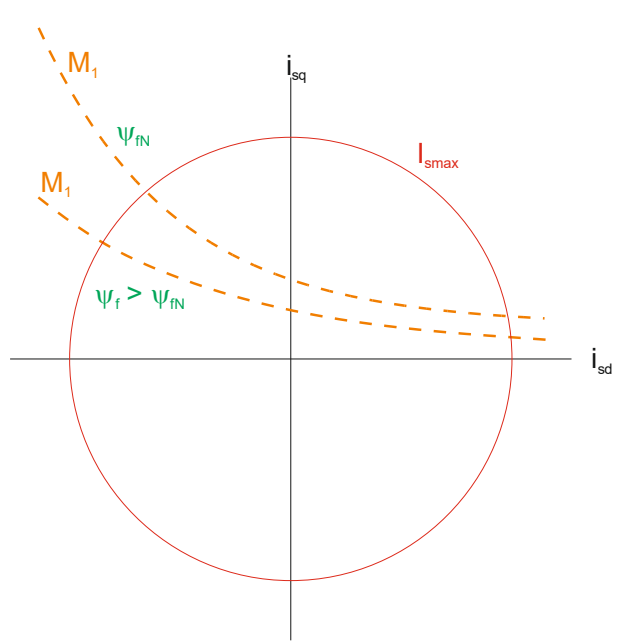

Figure 1. d,q-axis current diagram for different field flux linkage up to the base speed

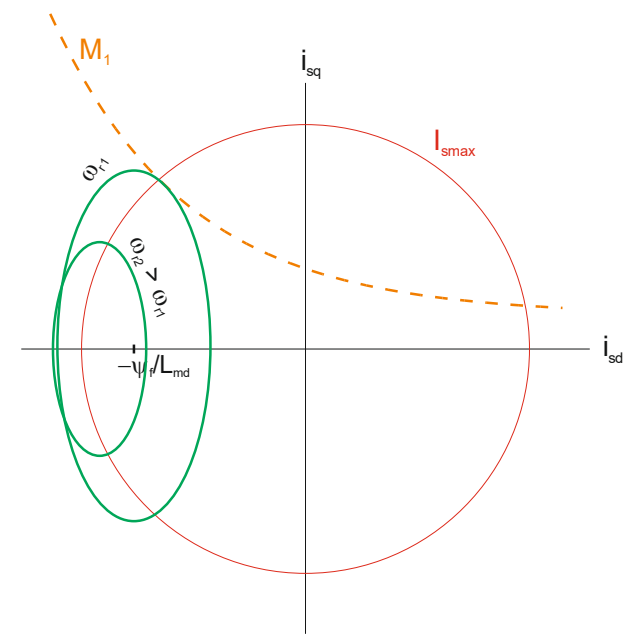

Figure 2. d,q-axis current diagram for different speeds in the field weakening range

\section{B. Simulation study}

For the determination of the optimal operating points for the maximal torque values, the simulation has been made by Cartesian vector control in current loop with depth modulation controller (input: modulation depth, demand: 1, output: demanded daxis current) during really slow transient effect under sinusoidal wave supply and constant voltage in converter dc-link. The detailed description of the vector control is featured in Fig. 4 and [11]. It is method how the optimal field current can be determined without relatively complex mathematics. The rotor current and flux controller can be used for the simple vector control for the machine, which is operated on the maximum torque values without any mathematical model.

The results are featured in Fig. 3 and 5. The slow transient is always depicted for constant speed and changing of the three current in accordance with the limitation rules. The Fig. 3 shows almost constant rotor current. Truthfully for the laboratory machine, the optimal rotor current is constant for all speeds, because the rotor-stator linkage changes. The final value of the rotor current refers to limit shift of the ellipse center to the maximal stator current. The next Fig. 5 refers the benefits of the optimal control. The torque for any speed is higher in comparison with the zero d-axis current control. Even for two maximal speeds, the feasible torque for zero d-axis is zero. It refers the wider speed range with the optimal control.

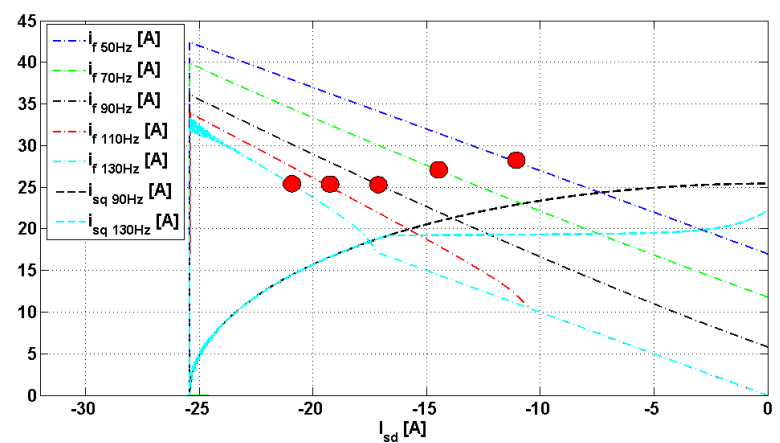

Figure 3. Current graphs for different stator frequency 


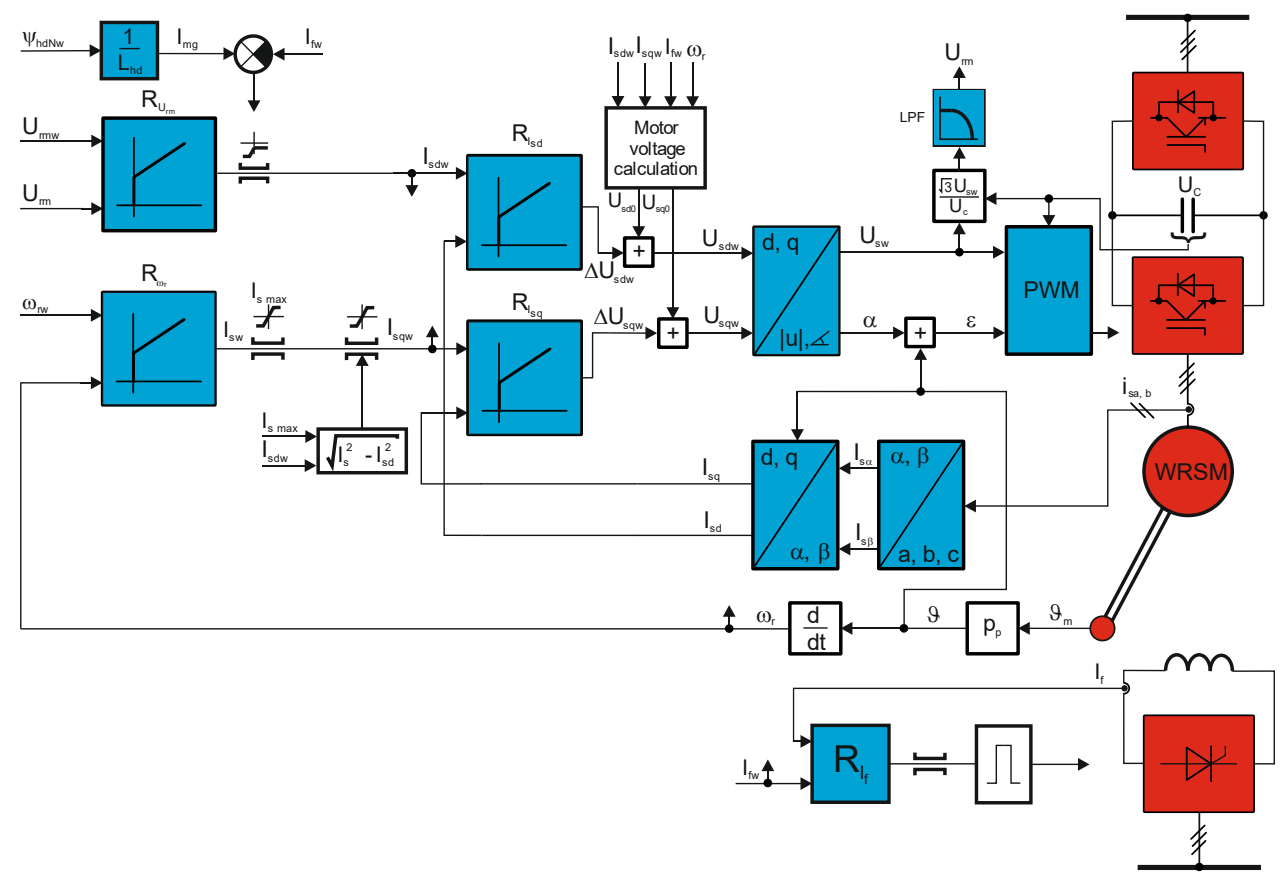

Figure 4. Vector control in Cartesian coordinates

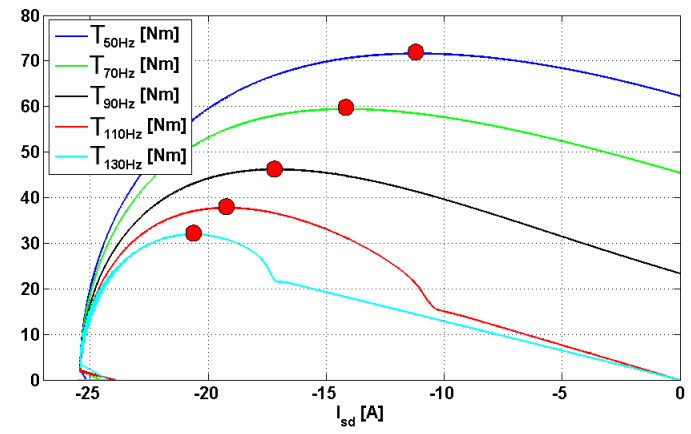

Figure 5. Torque graphs for different stator frequency

In reaction on common questions about the comparison of the optimal strategy and the classical approach to control the motor in reference frame tied to stator or magnetic flux linkage, thus to keep the outer or inner unity power factor, the same slow transients has been depicted see Fig. 6 and 7 .

Firstly, the difference between constant torque speed region and field weakening rang is evident. Up to the base speed (Fig. 6. $f_{s}=50 \mathrm{~Hz}$ ), the optimal operating point almost corresponds with the inner unity power factor. Whereas in the field weakening, the optimum agrees with the outer unity power factor see Fig. 7. The control oriented only on one flux linkage is not able to optimally operate under the whole speed range.

\section{EXPERIMENTAL TESTS}

The optimal control has been verified on the developed laboratory stand as specifies the next parameter table and motor depiction.

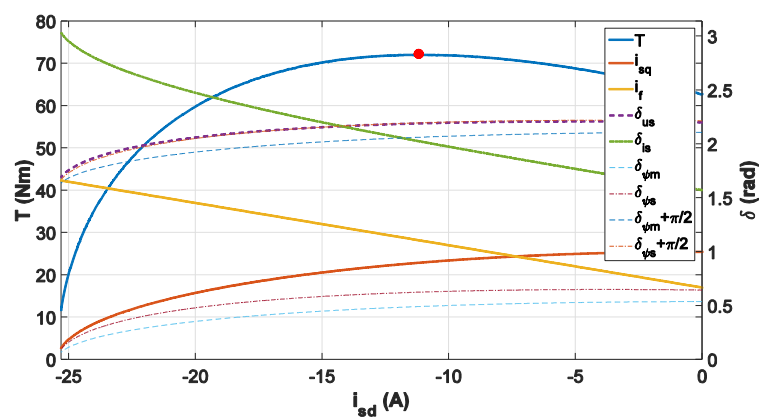

Figure 6. Torque, current and angle graphs for stator frequency $f_{s}=50 \mathrm{~Hz}$

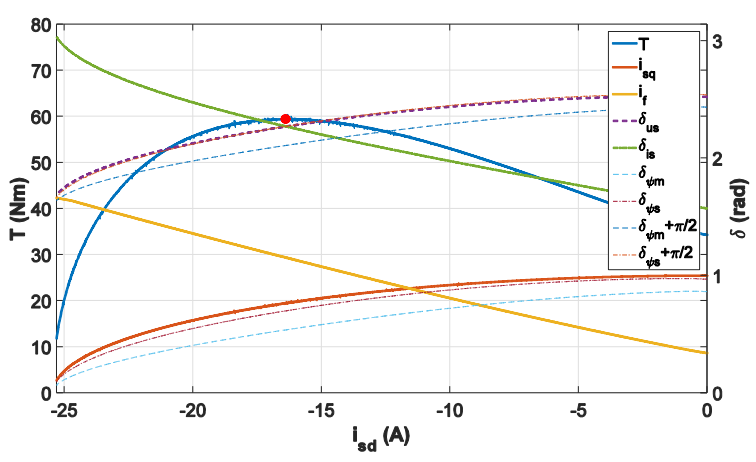

Figure 7. Torque, current and angle graphs for stator frequency $f_{s}=70 \mathrm{~Hz}$

TABLE I. MOTOR PARAMETERS

\begin{tabular}{|c|c|}
\hline Stator phase resistance & $R_{s}=0.28 \Omega$ \\
\hline Rotor resistance on rotor side & $R_{r}=6 \Omega$ \\
\hline d-axis stator inductance & $L_{s d}=60 \mathrm{mH}$ \\
\hline q-axis stator inductance & $L_{s q}=25 \mathrm{mH}$ \\
\hline Rotor rectifier input voltage & $U_{r e c}=80 \mathrm{Vrms}$ \\
\hline Number of pole pairs & $p_{p}=2$ \\
\hline Nominal stator current & $I_{s N}=18 \mathrm{~A}_{\mathrm{rms}}$ \\
\hline Nominal rotor current & $I_{r N}=2 \mathrm{~A}$ \\
\hline Converter dc-link voltage & $U_{c N}=700 \mathrm{~V}$ \\
\hline Maximal modulation depth & $U_{r m w}=0.2$ \\
\hline
\end{tabular}




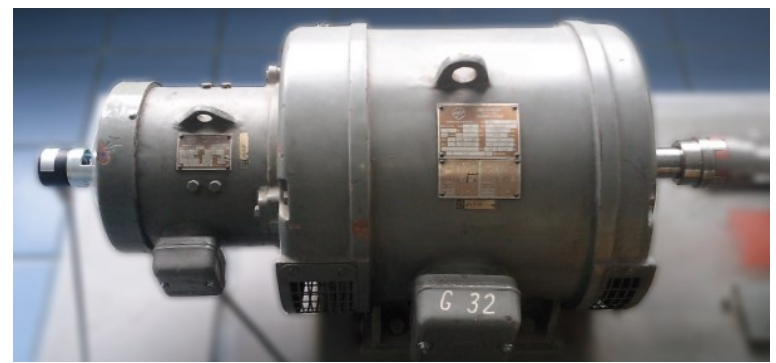

Figure 8. Laboratory WRSM with salient poles $-10 \mathrm{~kW}$

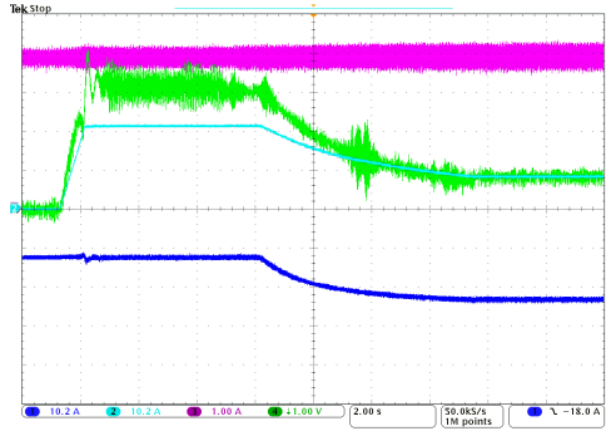

Figure 9. Speed up - Optimal control, $f_{s}=0-30 \mathrm{~Hz}$ : Ch1: d-axis current $I_{s d}[10.2 \mathrm{~A} / \mathrm{div}], \mathrm{Ch} 2$ : q-axis current $I_{s q}[10.2 \mathrm{~A} / \mathrm{div}]$, Ch3: field current $I_{f}[8.66 \mathrm{~A} / \mathrm{div}]$, Ch 4 : motor torque $T[20 \mathrm{Nm} / \operatorname{div}]$

The verification has been made by sensing of the motor torque and changing with the motor currents to find the torque maximum consistently with the simulation transients. From these tests, the optimal rotor current has been determined and used as demand for the vector control. Consequently, the drive speed up is shown in the Fig. 9. Real control operates with higher constant rotor current and lower torque than has been theoretically simulated. It refers to necessity to improve model of the motor. The comparison of any unity power factor control has not been made practically from the same reason, because the precise parameters are needed for the appropriate flux model and unity power factor cannot be precisely measured due to pulse wide modulated stator voltage and further the control variety is really small for this design of machine even in the simulations.

\section{CONCLUSIONS}

The main objective of this contribution is to answer on the question: Is a unity power factor control the same as the optimal maximum torque strategy? The answer is No, but for many drives the difference can be neglected. The more significant difference occurs for the lower loads (torques) of the motor, whose characteristics are theme for the future research.
This paper features mainly the simulation study, which is partly verified on the laboratory rig.

\section{ACKNOWLEDGMENT}

The research has been supported by the Ministry of Education, Youth and Sports of the Czech Republic under project LO1607 - RICE - New technologies and concepts for smart industrial system, the project of Technology Agency of the Czech Republic under project TE02000103 - Center for Intelligent Drives and Advanced Machine Control (CIDAM) and the project of Student Grant System SGS-2015-038.

\section{REFERENCES}

[1] M. Märgner and W. Hackmann, "Control challenges of an externally excited synchronous machine in an automotive traction drive application," Emobility - Electrical Power Train, 2010, Leipzig, 2010, pp. 1-6.

[2] H. S. Seol; J. M. Jeong; J. Lee; C. S. Jin, "Current Control of WRSM considering magnetic saturation phenomenon," in IEEE Transactions on Magnetics, vol.PP, no.99, pp.1-1.

[3] D. Uzel and Z. Peroutka, "Design of current reference generator for optimal control of interior permanent magnet motor," Applied Electronics (AE), 2011 International Conference on, Pilsen, 2011, pp. 1-4.

[4] D. Uzel and Z. Peroutka, "Optimal control and identification of model parameters of traction interior permanent magnet synchronous motor drive," IECON 2011 - 37th Annual Conference on IEEE Industrial Electronics Society, Melbourne, VIC, 2011, pp. 1960-1965.

[5] D. Uzel and Z. Peroutka, "Control and design considerations for wheel mounted drive of tram: Interesting features offered by IPMSM technology," Power Electronics and Motion Control Conference (EPE/PEMC), 2010 14th International, Ohrid, 2010, pp. T9-52-T9-58

[6] A. K. Jain and V. T. Ranganathan, "Modeling and Field Oriented Control of Salient Pole Wound Field Synchronous Machine in Stator Flux Coordinates," in IEEE Transactions on Industrial Electronics, vol. 58, no. 3, pp. 960-970, March 2011.

[7] S. P. Das and A. K. Chattopadhyay, "Observer based stator flux oriented vector control of cycloconverter-fed synchronous motor drive," Power Electronics, Drives and Energy Systems for Industrial Growth, 1996., Proceedings of the 1996 International Conference on, New Delhi, 1996, pp. 236-242 vol.1

[8] Guimei Wang, Qingdong Wang, Jiangbo Li and Jianfeng Wei, "Mine elevator comprehensive performance testing system based on virtual instrument," Industrial Electronics and Applications, 2008. ICIEA 2008. 3rd IEEE Conference on, Singapore, 2008, pp. 1027-1030.

[9] T. Nakano, H. Ohsawa and K. Endoh, "A High-Performance Cycloconverter-Fed Synchronous Machine Drive System," in IEEE Transactions on Industry Applications, vol. IA-20, no. 5, pp. 1278-1284, Sept. 1984.

[10] Y Xu , and J Jiang , "An Improved Flux Estimator for Gap Flux Orientation Control of DC-Excited Synchronous Machines", Journal of Power Electronics, vol. 2, no. 2, Mar 2015.

[11] D. Uzel, K. Zeman, Z. Peroutka and M. Danek, "Optimal vector control for wound rotor salient pole synchronous motor up to base speed," Power Electronics and Motion Control Conference (EPE/PEMC), 2012 15th International, Novi Sad, 2012, pp. DS2a.12-1-DS2a.12-8. 